\title{
Correction to: Genetic consequences of social dynamics in the Andean condor: the role of sex and age
}

\author{
Julian Padró $^{1,2}$. Jonathan N. Pauli ${ }^{2}$ Paula L. Perrig ${ }^{2} \cdot$ Sergio A. Lambertucci ${ }^{1}$
}

Published online: 22 July 2019

(C) Springer-Verlag GmbH Germany, part of Springer Nature 2019

\section{Correction to: Behavioral Ecology and Sociobiology https://doi.org/10.1007/s00265-019-2714-8}

The publisher regrets to inform the readers that the typesetter misinterpreted the correction from the author. The text 'In the case of the Andean condor, recent satellite tracking revealed that the home range of immature birds $\left(299,770 \mathrm{~km}^{2}\right)$ is more than twofold of that of adults $\left(>290,000 \mathrm{~km}^{2}\right)$ in northern Patagonia (Alarcón et al. 2017; Guido et al. 2017)' should have been 'In the case of the Andean condor, recent satellite tracking revealed that the home range of immature birds $\left(>290,000 \mathrm{~km}^{2}\right)$ is more than twofold of that of adults $\left(125,000 \mathrm{~km}^{2}\right)$ in northern Patagonia (Alarcón et al. 2017; Guido et al. 2017)'.

The original article has been corrected.

Pulisher's note Springer Nature remains neutral with regard to jurisdictional claims in published maps and institutional affiliations

The online version of the original article can be found at https://doi.org/ 10.1007/s00265-019-2714-8

Julian Padró

padrojulian@comahue-conicet.gob.ar; padro@wisc.edu

1 Grupo de Investigaciones en Biología de la Conservación, INIBIOMA (Universidad Nacional del Comahue-CONICET), Quintral 1250, R8400FRF Bariloche, Argentina

2 Department of Forest and Wildlife Ecology, University of Wisconsin-Madison, Linden 1630, Madison, WI 53706, USA 